\title{
Systemic immune-inflammation index in germ-cell tumours: search for a biological prognostic biomarker
}

\author{
Costantine Albany ${ }^{\star}, 1$ \\ ${ }^{1}$ Division of Hematology/Oncology, Indiana University School of Medicine, Indianapolis, IN, USA
}

Germ-cell tumours (GCTs) are collectively the most common cancer type in men aged 15-40 years, and they are a significant cause of morbidity and mortality in this population. Platinumbased chemotherapy has dramatically improved the outcome for patients with metastatic disease since the first patient was treated at Indiana University in 1974 (Einhorn \& Donohue, 1977); however, despite the high cure rate of $70-80 \%, \sim 20-30 \%$ of patients with metastatic disease will relapse after first-line chemotherapy (Albany et al, 2017a). The International Germ-Cell Cancer Collaborative Group (IGCCCG) classifies patients with metastatic GCT into good, intermediate, and poor risk groups based on three clinical prognostic criteria: primary tumour site, metastatic sites, and the amplitude of serum tumour marker levels (IGCCCG, 1997). However, these IGCCCG prognostic criteria are merely a reflection of the volume of disease rather than the pathology. Currently, no biological prognostic serum biomarker exists for this disease beyond the serum tumour markers alpha-fetoprotein (AFP) and beta-subunit of human chorionic gonadotropin (hCG), and these two markers do not predict who will relapse after chemotherapy. For example, patients with elevated AFP $(>10000 \mathrm{ng} / \mathrm{ml})$ or hCG $(>50000 \mathrm{IU} / \mathrm{L})$ are classified as poorrisk, with a $50 \%$ chance of cure following four cycles of bleomycin, etoposide and platinum (BEP) chemotherapy; however, we cannot predict whether a particular patient will respond to this chemotherapy. Thus, a biologically driven biomarker that reflects the pathogenesis is highly needed.

Recent studies have demonstrated the role of tumour microenvironmental inflammation in the proliferation and survival of malignant cells, angiogenesis, metastasis, subversion of adaptive immunity, and reduced response to chemotherapeutic agents; making inflammation one of the hallmarks of cancer (Hanahan \& Weinberg, 2011). The systemic immune-inflammation index (SII), which uses a simple calculation based on peripheral lymphocyte, neutrophil, and platelet counts, was recently investigated as a prognostic marker in several tumours (van Soest et al, 2015; Bhindi et al, 2016; Lolli et al, 2016). In this issue of the British Journal of Cancer, two articles highlight for the first time the prognostic significance of SII in patients with GCT. Fankhauser et al (2018) evaluated the prognostic value of SII in patients with metastatic GCT treated with cisplatin-based chemotherapy. The neutrophilto-lymphocyte ratio (NLR) was also calculated. NLR and SII were both independent predictors in a multivariable model of overall survival (OS) when tested separately against the IGCCCG risk classification.

Chovanec et al (2018) performed an interesting analysis, whereby they combined SII and the prognostic significance of PD-L1 expression on tumour infiltrating lymphocytes (TILs). These two measurements reflect different aspects of the immune environment; PD-L1's expression on TILs provides an insight into the tumour microenvironment, and SII indicates a global inflammatory status. The high expression of PD-L1 on TILs is a marker of T-cell exhaustion and could result in a reduced proinflammatory environment. It is currently unclear whether these two factors have a mechanistic connection; however, combining the two allowed the identification of a new subgroup of patients. Patients who showed high PD-L1 expression on TILs and low SII exhibited the best prognosis, with $100 \%$ cure rate and no relapses after chemotherapy. This is indeed a rare finding in the literature on GCTs.

In this era of targeted treatment for solid tumours, there is a lack of biomarkers for clinical management and therapeutic guidance in refractory GCT. Multiple clinical trials utilising targeted therapy in refractory GCT were disappointing, with individual patients only rarely achieving objective responses with brentuximab vedotin (Oing et al, 2016; Albany et al, 2017b). In part, this could be explained by the lack of clinically validated biomarkers and the molecular selection of patients prior to their enrolment in clinical trials (Kollmannsberger et al, 2017). MicroRNAs (miRNAs) have

*Correspondence: Dr C Albany; E-mail: calbany@iu.edu

Published online 27 February 2018

(C) 2018 Cancer Research UK. All rights reserved 0007 - 0920/18 
more recently surfaced as a potential biomarker in monitoring testicular cancer, with higher sensitivity and specificity when compared with AFP and hCG (Dieckmann et al, 2017); however, miRNAs are not prognostic and do not guide therapeutic decision.

Refining the prognosis of GCTs may begin with the newly emerged biomarkers highlighted in these two papers, such as the effect of PD-L1 on TILs and the SII. These novel GCT biomarkers could represent a substantial step forward after the lengthy period of stagnation in the understanding of GCT biology, and may hopefully open the door for the future discovery of biomarkerdriven treatments. A key and significant premise of the two papers is their focus on SII as a prognostic biomarker, which has the potential to be readily adopted into the clinic, as it only requires a simple complete blood count $(\mathrm{CBC})$. If prospectively validated, this could be a powerful yet simple tool to predict prognosis beyond the historical IGCCCG guidelines. Looking forwards, it will also be essential to look at whether SII is predictive for response to chemotherapy, especially in patients with poor-risk disease.

\section{CONFLICT OF INTEREST}

The author declares no conflict of interest.

\section{REFERENCES}

Albany C, Adra N, Snavely AC, Cary C, Masterson TA, Foster RS, Kesler K, Ulbright TM, Cheng L, Chovanec M, Taza F, Ku K, Brames MJ, Hanna NH, Einhorn LH (2017a) Multidisciplinary Clinic Approach Improves Overall survival outcomes of patients with metastatic germ cell tumors. Ann Oncol. e-pub ahead of print 10 November 2017; doi: 10.1093/ annonc/mdx731.

Albany C, Einhorn L, Garbo L, Boyd T, Josephson N, Feldman DR (2017b) Treatment of CD30-expressing germ cell tumors and sex cord stromal tumors with brentuximab vedotin: identification and report of seven cases. Oncologist 22: 1-9.

Bhindi B, Hermanns T, Wei Y, Yu J, Richard PO, Wettstein MS, Templeton A, Li K, Sridhar SS, Jewett MA, Fleshner NE, Zlotta AR, Kulkarni GS (2016)
Identification of the best complete blood count-based predictors for bladder cancer outcomes in patients undergoing radical cystectomy. $\mathrm{Br} \mathrm{J}$ Cancer 114: 207-212.

Chovanec M, Cierna Z, Miskovska V, Machalekova K, Kalavska K, Rejlekova K, Svetlovska D, Macak D, Spanik S, Kajo K, Babal P, De Giorgi U, Mego M, Mardiak J (2018) Systemic immune-inflammation index in germ-cell tumours. Br J Cancer 118: 831-838.

Dieckmann KP, Radtke A, Spiekermann M, Balks T, Matthies C, Becker P, Ruf C, Oing C, Oechsle K, Bokemeyer C, Hammel J, Melchior S, Wosniok W, Belge G (2017) Serum levels of microRNA miR-371a-3p: A sensitive and specific new biomarker for germ cell tumours. Eur Urol 71: 213-220.

Einhorn LH, Donohue J (1977) Cis-diamminedichloroplatinum, vinblastine, and bleomycin combination chemotherapy in disseminated testicular cancer. Ann Intern Med 87: 293-298.

Fankhauser CD, Sander S, Roth L, Gross O, Eberli D, Sulser T, Seifert B, Beyer J, Hermanns T (2018) Systemic inflammatory markers have independent prognostic value in patients with metastatic testicular germ cell tumours undergoing first-line chemotherapy. $\mathrm{Br} J$ Cancer 118: 825-830.

Hanahan D, Weinberg RA (2011) Hallmarks of cancer: the next generation. Cell 144: 646-674.

International Germ Cell Consensus Classification: a prognostic factor-based staging system for metastatic germ cell cancers (1997) International Germ Cell Cancer Collaborative Group. J Clin oncol 15: 594-603.

Kollmannsberger C, Nappi L, Nichols C (2018) Novel treatment options for refractory GCT: Back to the bench! Ann Oncol 29(1): 21-22.

Lolli C, Basso U, Derosa L, Scarpi E, Sava T, Santoni M, Crabb SJ, Massari F, Aieta M, Conteduca V, Maruzzo M, La Russa F, Wheater M, Berardi R, Galli L, De Giorgi U (2016) Systemic immune-inflammation index predicts the clinical outcome in patients with metastatic renal cell cancer treated with sunitinib. Oncotarget 7: 54564-54571.

Oing C, Kollmannsberger C, Oechsle K, Bokemeyer C (2016) Investigational targeted therapies for the treatment of testicular germ cell tumors. Expert Opin Investig Drugs 25: 1033-1043.

van Soest RJ, Templeton AJ, Vera-Badillo FE, Mercier F, Sonpavde G, Amir E, Tombal B, Rosenthal M, Eisenberger MA, Tannock IF, de Wit R (2015) Neutrophil-to-lymphocyte ratio as a prognostic biomarker for men with metastatic castration-resistant prostate cancer receiving first-line chemotherapy: data from two randomized phase III trials. Ann Oncol 26: 743-749. 